\title{
Nutritional situation among Syrian refugees hosted in Iraq, Jordan, and Lebanon: cross sectional surveys
}

S. M. Moazzem Hossain', Eva Leidman², James Kingori ${ }^{2}$, Abdullah Al Harun and Oleg O. Bilukha²

\begin{abstract}
Background: Ongoing armed conflict in Syria has caused large scale displacement. Approximately half of the population of Syria have been displaced including the millions living as refugees in neighboring countries. We sought to assess the health and nutrition of Syrian refugees affected by the conflict.

Methods: Representative cross-sectional surveys of Syrian refugees were conducted between October 2 and November 30, 2013 in Lebanon, April 12 and May 1, 2014 in Jordan, and May 20 and 31, 2013 in Iraq. Surveys in Lebanon were organized in four geographical regions (North, South, Beirut/Mount Lebanon and Bekaa). In Jordan, independent surveys assessed refugees residing in Za'atri refugee camp and refugees residing among host community nationwide. In Iraq, refugees residing in Domiz refugee camp in the Kurdistan region were assessed. Data collected on children aged 6 to 59 months included anthropometric indicators, morbidity and feeding practices. In Jordan and Lebanon, data collection also included hemoglobin concentration for children and nonpregnant women aged 15 to 49 years, anthropometric indicators for both pregnant and non-pregnant women, and household level indicators such as access to safe water and sanitation.
\end{abstract}

Results: The prevalence of global acute malnutrition among children 6 to 59 months of age was less than $5 \%$ in all samples (range 0.3-4.4\%). Prevalence of acute malnutrition among women 15 to 49 years of age, defined as mid-upper arm circumference less than $23.0 \mathrm{~cm}$, was also relatively low in all surveys (range 3.5-6.5 \%). For both children and non-pregnant women, anemia prevalence was highest in Za'atri camp in Jordan (48.4 \% and $44.8 \%$, respectively). Most anemia was mild or moderate; prevalence of severe anemia was less than or equal to $1.1 \%$ in all samples of children and women.

Conclusions: Despite the ongoing conflict, results from all surveys indicate that global acute malnutrition is relatively low in the assessed Syrian refugee populations. However, prevalence of anemia suggests a serious public health problem among women and children, especially in Za'atri camp. Based on these findings, nutrition partners in the region have reprioritized response interventions, focusing on activities to address micronutrient deficiencies such as food fortification.

Keywords: Syria, Refugee, Nutrition, Health, Survey

\footnotetext{
* Correspondence: eleidman@cdc.gov

${ }^{2}$ Emergency Response and Recovery Branch, Division of Global Health

Protection, Center for Global Health, Centers for Disease Control and

Prevention, Building 2500, Mailstop E-22, 2500 Century Parkway NE, Atlanta,

GA 30345, USA

Full list of author information is available at the end of the article
} 


\section{Background}

Armed conflict has spread throughout Syria, with warring parties, including government forces, non-state armed groups, and terrorist groups, fighting to expand their areas of influence and gain control of strategic roads, settlements and critical resources. In the sixth year of the conflict, violence in Syria has "neither abated nor diminished in brutality," according to the United Nations Security Council $[1,2]$.

The humanitarian consequences of this conflict are dramatic. According to United Nations (UN) and regional partners, Syria is the largest displacement crisis globally [3]. Entering the fourth year of the conflict, around the time of our assessments, an estimated 8.8 million people had been displaced, almost half the population of Syria [4]. Of them, more than a quarter have been forced to cross international borders and seek refuge in neighboring countries [4]. An estimated one in five registered refugees are children under 5 years of age [5].

Previous complex emergencies have demonstrated that conflict and displacement often result in a deterioration of the nutritional status of populations. In the context of prolonged conflict, affected populations often become dependent on humanitarian assistance for food and as a result experience reduced dietary diversity and meal frequency [6-8]. Separation of children from caretakers as a result of the conflict and displacement, also often affects infant and young child feeding (IYCF) practices $[9,10]$. Deterioration of water, sanitation, and health infrastructure, as well as access to key services can compound the effects of crisis on nutrition [11].

Potential for nutrition insecurity was of particular concern in Syria as assessments of the nutritional status of children prior to the conflict suggested some baseline deficiencies. According to the 2009 Syrian Family Health Survey (SFHS) and the 2006 Multiple Indicator Cluster Survey (MICS), levels of total wasting in Syria were greater than $8 \%$, poor by World Health Organization (WHO) Crisis Classifications [12-14]. Levels of stunting were greater than $20 \%$ in both assessments.

The scale of the displacement from Syria has further contributed to concerns about the nutritional status of displaced persons. Of the more than two million Syrian refugees displaced in 2013-14, the majority were hosted in Lebanon, Jordan, Turkey, and Iraq [4]. The displacement, in absolute terms and relative to the host population, has overwhelmed some of these neighboring countries. For example, Lebanon, a country of just over four million people, registered its millionth Syrian refugee shortly after the survey in Lebanon concluded [15].

While nutrition partners cautioned of a deteriorating situation in Syria, limited data existed at the time of our surveys. Better information was needed to inform the ongoing response-estimated at $\$ 30$ million in nutrition programming and $\$ 1.1$ billion in food and agriculture activities for 2014 [16]. This need prompted calls for rigorous and representative assessments to confirm the nutritional situation of Syrian refugees [17].

In this context, nutrition surveys were organized in Jordan, Lebanon and Iraq to generate evidence as to the nutritional status of Syrian refugees with a primary objective of assessing the level of acute malnutrition among women and children. Additional indicators including those related to anemia, access to health care, morbidity, IYCF practices, and water and sanitation helped contextualize these findings. Surveys in Lebanon, Jordan and Iraq also allowed us to compare whether the nutritional status of refugees depended on the country where refugees settled or the type of settlement (in refugee camps or integrated with host population).

\section{Methods}

Study design and sample size

Data used in this analysis were obtained from crosssectional surveys of Syrian refugees from seven sites in three countries: Lebanon, Jordan and Iraq. Data were obtained from the United Nations Children's Fund (UNICEF) in Lebanon and Iraq and the Office of the United Nations High Commissioner for Refugees (UNHCR) in Jordan. In Lebanon, independent survey samples were selected in the four geographical regions of the country: North, South, Beirut/Mount Lebanon and Bekaa. Since there were no established refugee camps in Lebanon, all surveyed refugees resided in host communities. In Jordan, two independent surveys were conducted: among refugees residing in Za'atri refugee camp and among refugees residing among host communities (outside of camps) nationwide. In Iraq, the survey was conducted among refugees residing in Domiz refugee camp in the Kurdistan region of Iraq. Data collection took place between October 2 and November 30, 2013 in Lebanon, April 12 and May 1, 2014 in Jordan and May 20 and 31, 2013 in Iraq.

For surveys in Jordan and Lebanon, sample sizes were calculated based on estimated prevalence of global acute malnutrition, required precision, and design effects which were informed by results of previous cross-sectional nutrition surveys-a September 2012 survey in Lebanon and a November 2012 survey in Jordan [18, 19]. Adjusting for non-response rate and household demographics, 340, 270, 330 and 260 households were randomly selected in the North, South, Beirut/Mount Lebanon and Bekaa regions of Lebanon, respectively. Similarly in Jordan, 337 and 515 households were selected in Za'atari Camp and in host community, respectively. Parameters used for estimating sample size in Lebanon and Jordan are provided in Additional file 1 . In Iraq, a 30 cluster by 30 children survey design was used [20]. 
A list of registered refugees and persons awaiting registration maintained by the UNHCR was used as a sampling frame for all surveys, since this database included the most updated information on recently arrived refugees. In all surveys, the UNHCR database was used to select clusters randomly, proportional to the number of refugees residing in each administrative area or camp section. In non-camp settings, households within each cluster were randomly selected from the UNHCR database and called in advance of the field visit to confirm their availability, willingness to participate, and current address. In Jordan, $83 \%$ of households in the database had functional phone numbers. In both of the refugee camps (Domiz in Iraq and Za'atari in Jordan), households were systematically selected; sampling intervals were calculated using household listings by block obtained from community leaders or local health volunteers.

\section{Measurements}

The information on household, children and women was collected by teams that included both nationals and Syrian refugees. Teams composed of at least three members each (an interviewer, anthropometry measurer(s), and a hemoglobin $(\mathrm{Hb})$ technician where $\mathrm{Hb}$ was measured) received between 2 and 7 days of training, including a field test. All surveys collected data on basic demographics, anthropometry, recent illness, breastfeeding practices, and household level indicators related to water and sanitation. The surveys in Jordan and Lebanon also collected data on $\mathrm{Hb}$ concentration, food security and access to antenatal care (ANC). Household level indicators were excluded from the analysis of Iraq data, as the Domiz sample only included households with children under 5 years of age, and therefore was not a representative sample of all households in the camp.

$\mathrm{Hb}$ concentration was measured in children aged 6 to 59 months and non-pregnant women of reproductive age (15-49 years). Pregnancy status was self-reported. Hemoglobin was measured in capillary blood using a HemoCue $\mathrm{Hb} 301+$ photometer following a standard procedure [21]. Anemia in children was classified according to WHO definitions as severe (hemoglobin $<7 \mathrm{~g} /$ $\mathrm{dL})$, moderate $(7 \mathrm{~g} / \mathrm{dL} \leq$ hemoglobin $<10 \mathrm{~g} / \mathrm{dL})$, or mild $(10 \mathrm{~g} / \mathrm{dL} \leq$ hemoglobin $<11 \mathrm{~g} / \mathrm{dL})$ [22]. In non-pregnant women, anemia was classified as severe (hemoglobin < $8 \mathrm{~g} / \mathrm{dL})$, moderate $(8 \mathrm{~g} / \mathrm{dL} \leq$ hemoglobin $<11 \mathrm{~g} / \mathrm{dL})$, or mild $(11 \mathrm{~g} / \mathrm{dL} \leq$ hemoglobin $<12 \mathrm{~g} / \mathrm{dL})[22]$.

Anthropometry indicators in children aged 6 to 59 months were measured following standard procedures [23]. Weight was measured with a digital Seca scale, accurate to $0.1 \mathrm{~kg}$. Height or recumbent length was measured with a wooden ShorrBoard, accurate to $1 \mathrm{~mm}$. Children's age was ascertained from UNHCR registration cards or, if unavailable, from immunization cards, birth certificates, or caregiver recall. Presence of bilateral pitting edema was assessed by survey teams; all suspect cases were verified by a supervisor. Acute malnutrition (based on weight-for-height $\mathrm{z}$-score and the presence of edema), stunting (based on height-forage $\mathrm{z}$-score), and underweight (based on weight-for-age $\mathrm{z}$-score) were defined and classified as moderate $(-3 \leq \mathrm{z}$ score $<-2)$ and severe ( $\mathrm{z}$-score $<-3)$ according to WHO definitions [24]. Extreme outliers, defined using a flexible exclusion range criterion $( \pm 4 \mathrm{z}$-scores from the observed mean) were excluded from the analysis [25, 26]. Surveys assessed nutritional status of all women of reproductive age (15 to 49 years), classifying women with a mid-upper arm circumference (MUAC) less than $23.0 \mathrm{~cm}$ as malnourished [27].

Additional indicators were ascertained by self-report. Diarrhea was defined as three or more loose or watery stools in a 24-h period during the preceding 2 weeks. Current breastfeeding included children put to breast during the previous $24-\mathrm{h}$ period. In Lebanon and Iraq both indicators were assessed among all children 0-59 months; in Jordan children 0-5 months were not assessed for diarrhea. Access to antenatal care and iron-folic acid supplements was assessed in all pregnant women (15-49 years). A refugee household living outside of a refugee camp was considered to be hosted if they were residing in the same dwelling as citizens of the host country at the time of the assessment. Survey instruments were modified in each country to meet the information needs of the ongoing response; indicators not collected consistently across settings were excluded.

In Jordan, data were collected on mobile phones with an Android OS and uploaded daily. Anthropometric measurements were recorded on both the phone and paper allowing supervisors to verify data entry. In Lebanon and Iraq, all data were recorded on paper questionnaires.

\section{Statistical analysis}

For all surveys, ENA for SMART software 2011 (Version: Aug. 4, 2014) [28] was used to generate standardized zscores based on the 2006 WHO Growth Standards and analyze anthropometry data [24]. Additional variables were analyzed with EPI INFO 3.5.3 software, SPSS version 17.0, and STATA/IC 13.1. Ninety-five percent confidence intervals were calculated adjusting for the complex survey design. Significance was tested adjusting for clustering using the procedure described by Donner et al. [29] A $p$-value $<0.05$ was considered statistically significant.

\section{Results}

Survey samples

Final sample in Jordan included 329 households in Za'atari (response rate of $97.6 \%$ ) and 504 households 
in the host community (response rate of $97.9 \%$ ). In Lebanon, 326 (response rate of $95.9 \%$ ), 264 (response rate of $97.8 \%$ ), 327 (response rate of $99.1 \%$ ) and 255 (response rate of $98.1 \%$ ) households were assessed in North, South, Beirut/Mount Lebanon and Bekaa, respectively. These households included an average of 1.1 children aged 0-59 months per household in Jordan and an average of 1.3 children aged 0-59 months per household in Lebanon. In Iraq, 944 children 0-59 months were included. The number and demographics of children in each sample are presented in Table 1.

Women aged 15-49 years were assessed in surveys conducted in Jordan and Lebanon. The samples in Jordan included 359 women (of them, $12.5 \%$ pregnant) in Za'atri and 704 women (10.5\% pregnant). In Lebanon, survey samples included 567 women (11.3\% pregnant) in the North, 437 women (13.5\% pregnant) in the South, 527 women (10.8\% pregnant) in Beirut/ Mount Lebanon, and 405 women (12.6\% pregnant) in Bekaa (Table 1).

\section{Anthropometry}

Findings suggest that the prevalence of global acute malnutrition (GAM) among children was low among Syrian refugees across the region, less than $5 \%$ in all samples (range 0.3-4.4\%) (Table 2). In all samples in Jordan and Lebanon the means of weight-for-height (WHZ) z-score were higher than zero (range 0.23-0.39), indicating that the populations were slightly overweight compared to the WHO standard population. Mean WHZ z-score in Domiz was approximately zero $(-0.02)$.

Prevalence of chronic malnutrition (stunting) was lower among refugee children in the host population in Jordan (10.5\%) compared to other surveys (range 14.1$21.0 \% ; p<0.05$ compared to Iraq Domiz, Lebanon
Bekaa, North and South). Mean height-for-age (HAZ) zscore ranged from -0.59 to -1.07 (Table 2).

Prevalence of acute malnutrition based on MUAC among women 15-49 is presented in Table 3. As with acute malnutrition in children, there was little variability between surveys in the prevalence of low MUAC among women, and the prevalence was relatively low in all surveys (range $3.5-6.5 \%$ ).

\section{Anemia}

Anemia prevalence in children and non-pregnant women is presented in Tables 3 and 4, respectively. Anemia prevalence was higher in Za'atri camp compared to the other six surveys $(p<0.05$ for all); in both children and women, total anemia in Za'atri camp exceeded $40 \%$ (48.4\% and $44.8 \%$, respectively). Prevalence of total anemia among children in the non-camp refugee populations in Jordan $(26.1 \%)$ was comparable to the prevalence among children in Lebanon (range 13.9 to $25.8 \%$ ) ( $p>$ 0.05 except for Bekaa). Similarly, the prevalence of anemia among women in the non-camp refugee populations in Jordan (31.1\%) was comparable to the prevalence among women in Lebanon (range 18.4 to $29.3 \%)$ ( $p>0.05$ except for Bekaa).

Only one child in 6 surveys was classified as having severe anemia. Prevalence of severe anemia was less than or equal to $1.1 \%$ in all samples of non-pregnant women. The mean hemoglobin level was equal to or greater than $11.0 \mathrm{~g} / \mathrm{dL}$ for all samples of children and $12.0 \mathrm{~g} / \mathrm{dL}$ for all samples of women.

The prevalence of total anemia was higher among children aged 6-23 months compared to children aged 2459 months in all samples $(p<0.05$ except for Beirut and South). In North and Bekaa Lebanon the prevalence of total anemia among younger children was nearly three

Table 1 Survey sample characteristics, Syrian refugees in Jordan, Lebanon and Iraq, 2013-2014

\begin{tabular}{|c|c|c|c|c|c|c|c|}
\hline \multirow[b]{2}{*}{ Characteristic } & \multicolumn{2}{|l|}{ Jordan 2014} & \multicolumn{4}{|c|}{ Lebanon 2013} & \multirow{2}{*}{$\begin{array}{l}\text { Iraq } 2013 \\
\text { Domiz } \\
\text { (Refugee Camp) }\end{array}$} \\
\hline & $\begin{array}{l}\text { Za'atri } \\
\text { (Refugee Camp) }\end{array}$ & $\begin{array}{l}\text { National } \\
\text { (Outside Camp) }\end{array}$ & North & South & Beirut & Bekaa & \\
\hline Number of Households in Sample & 329 & 504 & 326 & 264 & 327 & 255 & - \\
\hline Number of Children (0-59 mo) in Sample & 355 & 541 & 409 & 329 & 465 & 332 & 944 \\
\hline \multicolumn{8}{|l|}{ Age (mo) -number (\%) of survey sample } \\
\hline $0-5$ & $28(7.9)$ & $58(10.7)$ & $31(7.6)$ & $19(5.8)$ & $42(9.0)$ & $24(7.2)$ & $104(11.0)$ \\
\hline $6-23$ & $115(32.4)$ & $166(30.7)$ & $132(32.3)$ & $109(33.1)$ & $127(27.3)$ & $103(31.0)$ & $488(51.7)$ \\
\hline $24-59$ & $212(59.7)$ & $317(58.6)$ & $236(57.7)$ & $196(59.6)$ & $291(62.6)$ & $203(61.1)$ & $352(37.3)$ \\
\hline Male Sex & $185(52.1)$ & $279(51.6)$ & $182(44.5)$ & $144(43.8)$ & $241(51.8)$ & $166(50.0)$ & 466 (49.4) \\
\hline Median age - mo & 29 & 29 & 28 & 31 & 29 & 29 & 26 \\
\hline $\begin{array}{l}\text { Number of Women (15-49 years) number (\%) } \\
\text { of survey sample }\end{array}$ & 359 & 704 & 567 & 437 & 527 & 405 & \\
\hline Non-pregnant & $314(87.5)$ & $630(89.5)$ & $503(88.7)$ & $378(86.5)$ & $470(89.2)$ & $354(87.4)$ & - \\
\hline Pregnant & $45(12.5)$ & 74 (10.5) & $64(11.3)$ & $59(13.5)$ & $57(10.8)$ & $51(12.6)$ & - \\
\hline
\end{tabular}


Table 2 Prevalence of malnutrition and mean anthropometry scores among children 6-59 months of age, Syrian refugees in Jordan, Lebanon and Iraq, 2013-2014

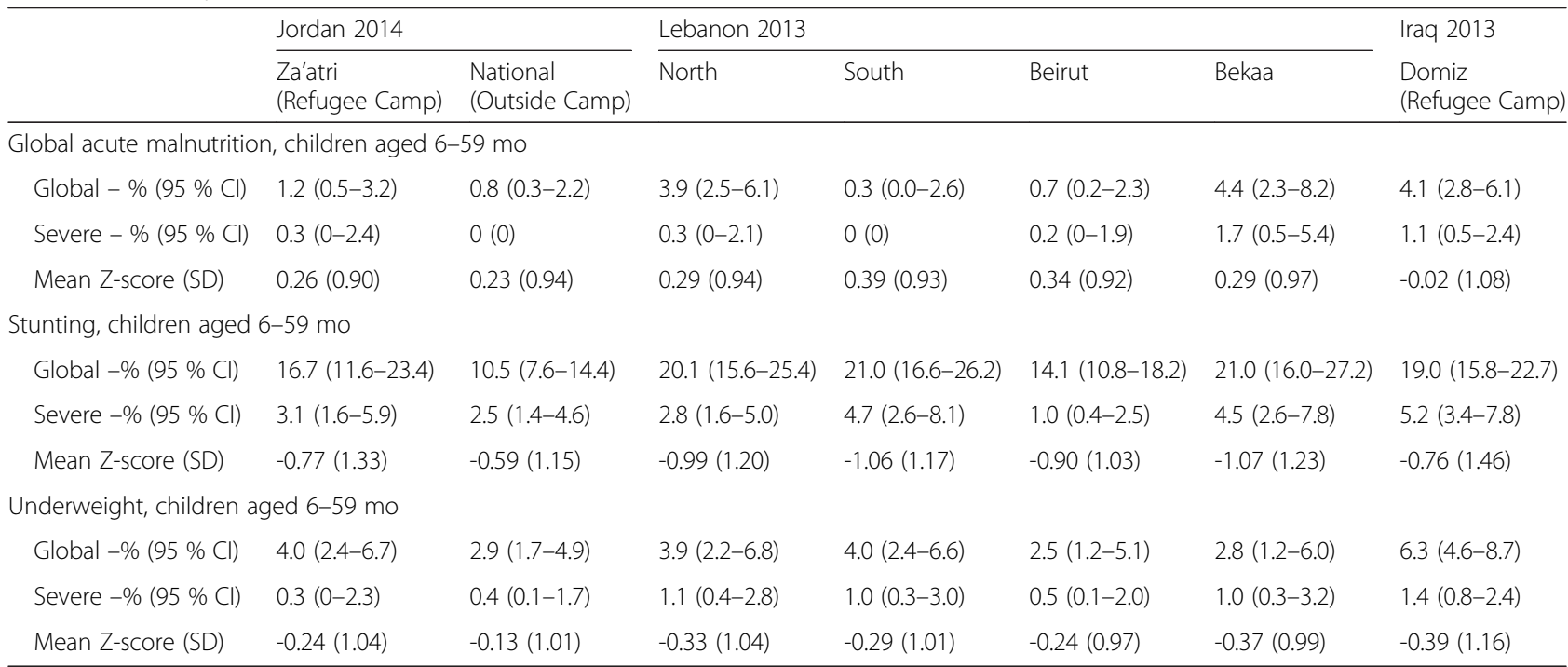

times that of older children $(42.9 \%$ and $14.1 \%$ in North, $24.1 \%$ and $8.2 \%$ in Bekaa, respectively). Mean hemoglobin ranged from 10.5 to $11.8 \mathrm{~g} / \mathrm{dL}$ among younger children (6-23 months) and 11.2 to $12.5 \mathrm{~g} / \mathrm{dL}$ for older children (24-59 months). The prevalence of anemia among non-pregnant women was similar to that in children ( $p>0.05$ in all surveys except Beirut).

\section{Antenatal care}

$29.7 \%$ of pregnant women living among the host population in Jordan reported being enrolled in antenatal care, a lower proportion than $53.3 \%$ enrollment reported in the Za'atri camp in Jordan $(p<0.05)$. Enrollment in Za'atri camp was similar to that reported in Lebanon surveys (range 44.4-52.5\%, $p>0.05$ for all). Enrollment in antenatal care did not exceed $55 \%$ in any of the surveys (Table 3).

The proportion of pregnant women receiving iron-folic pills ranged from $32.8 \%$ in South Lebanon to $44.0 \%$ in Bekaa. The number of women receiving iron-folic supplements represented a subset of women enrolled in antenatal care in all samples except in the host population in Jordan. In this sample, more women received iron-folic than reported enrollment in ANC (Table 3).

Table 3 Anemia prevalence and access to antenatal care in women 15-49 years of age, Syrian refugees in Jordan and Lebanon, $2013-2014^{\mathrm{a}}$

\begin{tabular}{|c|c|c|c|c|c|}
\hline \multicolumn{2}{|l|}{ Jordan 2014} & \multicolumn{4}{|c|}{ Lebanon 2013} \\
\hline $\begin{array}{l}\text { Za'atri } \\
\text { (Refugee Camp) }\end{array}$ & $\begin{array}{l}\text { National } \\
\text { (Outside Camp) }\end{array}$ & North & South & Beirut & Bekaa \\
\hline
\end{tabular}

\begin{tabular}{|c|c|c|c|c|c|c|}
\hline \multicolumn{7}{|c|}{ Mid-upper arm circumference (<23 cm) (All Women 15-49 yrs.) } \\
\hline Total (15-49 years) & $5.1(4.7-5.6)$ & $3.5(2.4-4.5)$ & $5.3(3.7-7.4)$ & $6.5(4.5-9.3)$ & $4.4(2.9-6.6)$ & $3.7(2.2-6.0)$ \\
\hline \multicolumn{7}{|l|}{ Anemia (Non-pregnant women 15-49 yrs.) } \\
\hline Total anemia $(\mathrm{Hb}<12.0 \mathrm{~g} / \mathrm{dL})$ & $44.8(38.5-51.0)$ & $31.1(27.2-35.0)$ & $27.7(22.3-33.2)$ & $27.0(20.0-34.2)$ & $29.3(24.0-34.6)$ & $18.4(12.6-24.1)$ \\
\hline Mild anemia $(\mathrm{Hb}<11.0-11.9 \mathrm{~g} / \mathrm{dL})$ & $21.2(16.7-25.7)$ & $17.6(14.6-20.7)$ & $13.6(8.7-18.5)$ & $14.0(7.4-20.7)$ & $16.2(12.0-20.3)$ & $10.1(5.2-15.0)$ \\
\hline Moderate anemia $(\mathrm{Hb}<8.0-10.9 \mathrm{~g} / \mathrm{dL})$ & $22.5(17.5-27.5)$ & $12.9(10.7-15.2)$ & $14.1(9.8-18.4)$ & $11.8(7.7-16)$ & $12.2(8.1-16.3)$ & $7.6(3.8-11.4)$ \\
\hline Severe anemia $(\mathrm{Hb}<8.0 \mathrm{~g} / \mathrm{dL})$ & $1.0(0-2.4)$ & $0.5(0-1.0)$ & 0 & $1.1(0-2.7)$ & $0.9(0-2.1)$ & $0.6(0-2.0)$ \\
\hline \multicolumn{7}{|c|}{ Hb (g/L) (Non-pregnant women 15-49 yrs.) Mean +/- SD } \\
\hline Total (15-49 y) & $12.0(1.51)$ & $12.6(1.48)$ & $12.6(1.36)$ & $12.6(1.53)$ & $12.5(1.65)$ & $13.3(1.57)$ \\
\hline \multicolumn{7}{|c|}{ Access to antenatal health care (Pregnant women 15-49 yrs.) } \\
\hline Currently enrolled in ANC & $53.3(35.2-71.4)$ & $29.7(16.2-43.3)$ & $50.8(36.5-65.1)$ & $52.5(37.5-67.6)$ & $44.4(31.2-57.7)$ & $45.1(26.1-64.1)$ \\
\hline Received iron-folic acid pill & $37.8(22.9-52.3)$ & $42.5(29.7-55.2)$ & $33.9(18.9-48.9)$ & $32.8(20.2-45.3)$ & $37.7(19.9-55.5)$ & $44.0(28.9-60.3)$ \\
\hline
\end{tabular}


Table 4 Anemia prevalence in children 6-59 months of age and mean hemoglobin levels, Syrian refugees in Jordan and Lebanon, 2013-2014

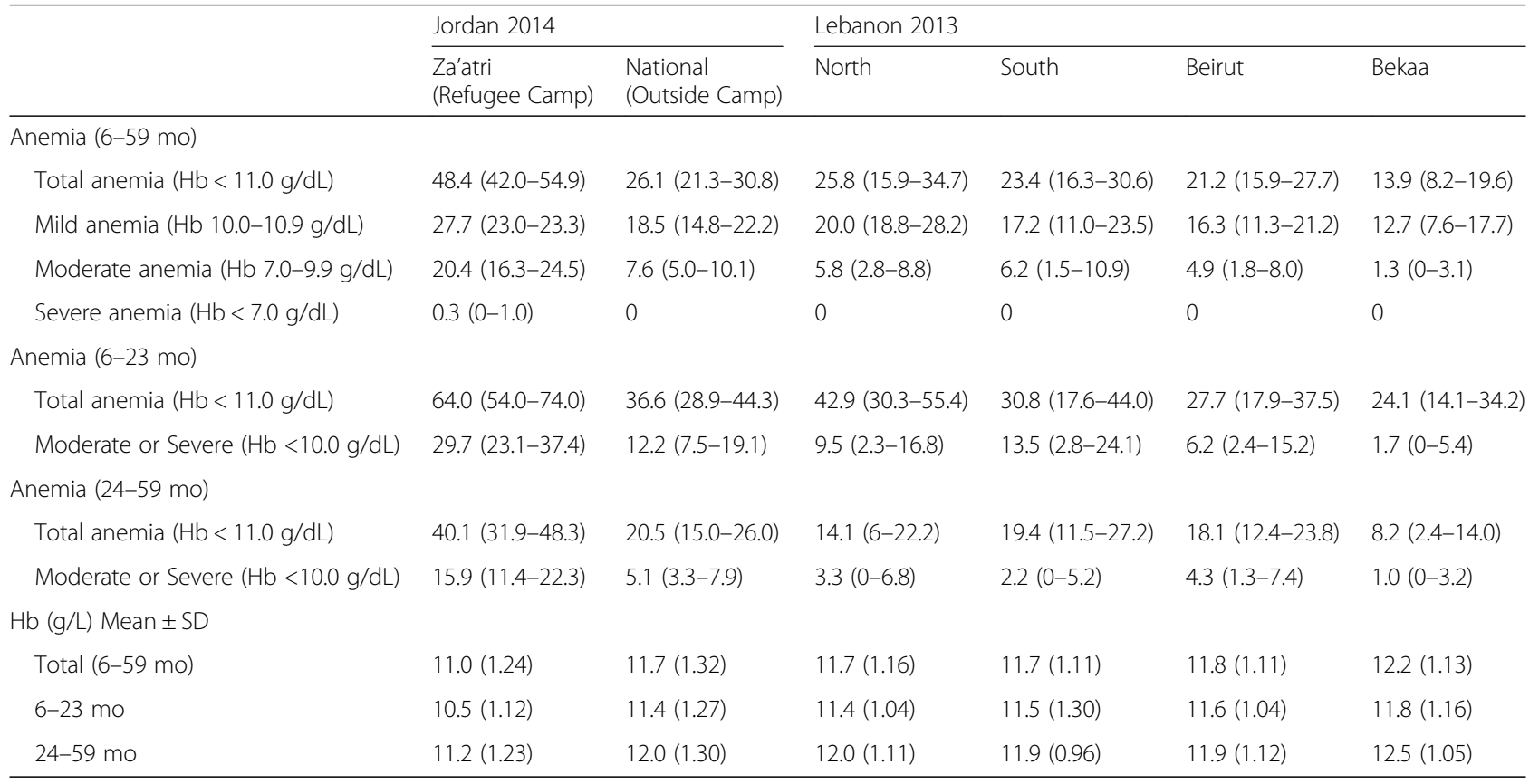

$\mathrm{Hb}$ hemoglobin

${ }^{\mathrm{a}}$ Data are presented as prevalence $(95 \% \mathrm{Cl})$ unless noted otherwise

\section{Child morbidity and breastfeeding}

The reported 2-week cumulative incidence of diarrhea was highest in North Lebanon (33.3 \%) and the two refugee camps, Domiz (32.8 \%) and Za'atri (27.0\%). The cumulative incidence in Za'atri was nearly twice that of refugees living among the host population in Jordan $(p<$ $0.05)$. The cumulative incidence of diarrhea was consistently higher among younger children (0-23 months in Lebanon, 6-23 months in Jordan) than older children (24-59 months) $(p<0.05$ except for Lebanon North and Iraq Domiz) (Table 5).

Current breastfeeding was assessed for all children aged 0-23 months. Prevalence was highest among the youngest cohort (children aged 0-5 months) and declined after 5 months of age in all samples. Current breastfeeding among children under two was lower in Domiz camp (44.5\%) compared to other surveys (range $57.8-68.1 \%, p<0.05$ for all). In both camps, the proportion of currently breastfed children declined sharply after 1 year of age, to $24.5 \%$ of children aged 12-23 months in Za'atri and to $25.1 \%$ of children aged 12-23 months in Domiz (Table 5).

\section{Water, sanitation, and accommodations}

Main source of drinking water, a proxy for access to safe drinking water, is presented in Table 6. The main source of drinking water in Za'atri camp was shared water tanks (sourced by tanker trucks), reported by $76.9 \%$ of refugees. For refugees living among host populations in Jordan and Lebanon municipal tap water and bottled water were the primary source; tanked water was an uncommon source, reported to be the primary source of water by less than $2 \%$ households. Bottled water was more common than tap water among refugees residing out of camp in Jordan (56.5\% and $38.4 \%$, respectively) and in Beirut/Mount Lebanon $(64.0 \%$ and $26.8 \%$ respectively); the reverse was true in North, South and Bekaa regions of Lebanon. Boreholes were another notable source of water in Lebanon, reported to be the main source of water for $16.3 \%$ of households in Bekaa and $20.4 \%$ in North Lebanon.

The majority of households in all samples had access to private toilets, including refugees in Za'atri refugee camp. Within Za'atri camp, less than a third (31.1\%) of the population relied on public toilet blocks or toilets in public places like markets or clinics. Private, individual or shared toilets were reported to be more common, used by $38.2 \%$ and $18.5 \%$ of households, respectively. For refugees living among the host population, the majority (range $56.3 \%$ to $72.7 \%$ ) of household had at least one private toilet per household. Private toilets were often shared in dwellings shared by more than one household.

The majority of refugee households in Lebanon and Jordan residing outside of a refugee camp were not sharing accommodations with either host nationals or other refugees (range $59.5 \%$ to $68.9 \%$ ). Cohabiting with host 
Table 5 Health and nutrition of children aged 0-23 months, by location

\begin{tabular}{|c|c|c|c|c|c|c|c|}
\hline & \multicolumn{2}{|l|}{ Jordan 2014} & \multicolumn{4}{|l|}{ Lebanon 2013} & \multirow{2}{*}{$\begin{array}{l}\text { Iraq } 2013 \\
\text { Domiz } \\
\text { (Refugee Camp) }\end{array}$} \\
\hline & $\begin{array}{l}\text { Za'atri } \\
\text { (Refugee Camp) }\end{array}$ & $\begin{array}{l}\text { National } \\
\text { (Outside Camp) }\end{array}$ & North & South & Beirut & Bekaa & \\
\hline \multicolumn{8}{|c|}{ Two week prevalence of diarrhea - \% (95 \% Cl) } \\
\hline Total (0-59 mo) & $27.0(21.1-33.9)^{a}$ & $14.5(11-18.8)^{\mathrm{a}}$ & $33.3(26.4-41.1)$ & $23.6(18.3-29.9)$ & $17.2(12.3-23.5)$ & $26.7(21.0-33.3)$ & $32.8(25.6-40.9)$ \\
\hline $0-23$ mo & $39.1(29.6-49.6)^{\mathrm{a}}$ & $21.1(14.9-28.9)^{\mathrm{a}}$ & $38.0(28.7-48.4)$ & $36.7(29.8-44.2)$ & $25.0(17.5-34.3)$ & $39.4(32.3-46.9)$ & $37.5(29.4-46.4)$ \\
\hline $24-59 \mathrm{mo}$ & $20.4(14.2-28.3)$ & $11.0(7.9-15.3)$ & $30.1(23.0-38.3)$ & $15.0(9.5-22.7)$ & $12.7(8.0-19.7)$ & $18.7(12.4-27.3)$ & $29.4(22.1-37.9)$ \\
\hline \multicolumn{8}{|c|}{ Current breastfeeding practice - \% (95 \% Cl) } \\
\hline Total (0-23 mo) & $66.7(57.6-74.7)$ & $68.1(59.8-75.3)$ & $57.8(47.7-67.3)$ & $62.0(49.8-72.8)$ & $65.6(56.2-74.0)$ & $60.0(47.2-71.6)$ & $44.5(40.2-48.9)$ \\
\hline $0-5 \mathrm{mo}$ & 100 & $94.4(77.8-98.8)$ & $88.0(71.8-95.5)$ & $93.8(57.3-99.4)$ & $93.1(73.3-98.5)$ & $84.6(46.5-97.2)$ & $78.6(68.7-86.1)$ \\
\hline 6-11 mo & $97.4(82.0-99.7)$ & $86.4(73.1-93.7)$ & $61.3(40.7-78.5)$ & 70.8 (51.9-84.6) & $80.0(61.7-90.9)$ & $71.4(48.0-87.1)$ & $58.2(48.6-67.2)$ \\
\hline $12-23 \mathrm{mo}$ & $24.5(14.2-39.0)$ & $44.1(32.1-56.9)$ & $43.3(29.9-57.8)$ & $48.1(30.8-65.8)$ & $45.3(35.1-56.0)$ & $46.3(30.9-62.5)$ & $25.1(20.2-30.7)$ \\
\hline
\end{tabular}

Prevalence of diarrhea in Jordan was not assessed among children 0-5 months of age

nationals was less common in Jordan $(2.3 \%$ of households) compared to samples in Lebanon (range $8.3 \%$ to $13.2 \%)$. Refugees residing in host community were more likely to be cohabiting with other refugees than with host nationals.

\section{Discussion}

Data presented here suggest that despite the magnitude of the crisis, Syrian refugees have not experienced elevated rates of acute malnutrition. Among both women and children, the prevalence of acute malnutrition was relatively low. Global acute malnutrition prevalence among children aged 6 to 59 months was less than the WHO threshold of "acceptable" $(<5 \%)$ in all settings [13].
Prevalence of acute malnutrition among women, as measured by mid-upper arm circumference, also indicated relatively low levels of wasting (range 3.5-6.5 \%).

Taken together, these data provide a more comprehensive picture of acute malnutrition among Syrian refugees affected by the conflict. Data on the nutrition status of displaced persons within Syria remains sparse given security and access restraints. One of the few representative surveys, a survey of children 6 to 59 months of age in Idleb governorate in June 2014, found that the prevalence of global acute malnutrition was $1.1 \%$, consistent with the low prevalence we observed among refugee populations [30]. The levels of acute malnutrition observed, however are notably lower than the prevalence

Table 6 Water, sanitation, and accommodations of refugee households, Syrian refugees in Jordan and Lebanon, 2013-2014

\begin{tabular}{|c|c|c|c|c|c|c|}
\hline & \multicolumn{2}{|l|}{ Jordan 2014} & \multicolumn{4}{|l|}{ Lebanon 2013} \\
\hline & $\begin{array}{l}\text { Za'atri } \\
\text { (Refugee Camp) }\end{array}$ & $\begin{array}{l}\text { National } \\
\text { (Outside Camp) }\end{array}$ & North & South & Beirut & Bekaa \\
\hline \multicolumn{7}{|l|}{ Main source of drinking water - \% (95 \% Cl) } \\
\hline Running Water (Tap) & $10.5(46-22.1)$ & $38.4(29.7-47.9)$ & $44.4(35.1-54.2)$ & $54.4(44.2-64.2)$ & $26.8(17.9-38.0)$ & $44.3(36.0-52.9)$ \\
\hline Bottled (purchased) water & $12.6(7.9-19.5)$ & $56.5(46.7-65.8)$ & $14.8(10.7-21.6)$ & $31.9(23.1-42.3)$ & $64.0(52.5-74.1)$ & $19.4(11.2-31.4)$ \\
\hline Water tank or tanker truck & $76.9(64.6-85.9)$ & $2.0(0.9-4.5)$ & 0 & 0 & 0 & $0.4(0-3.1)$ \\
\hline Other & 0 & $3.2(1.7-6)$ & $40.7(30.9-51.4)$ & $13.7(9.4-19.4)$ & $9.2(5.6-14.9)$ & $36.0(29.1-43.5)$ \\
\hline \multicolumn{7}{|l|}{ Primary toilet used by household - \% (95 \% Cl) } \\
\hline Public Toilet & $31.1(20.6-43.9)$ & $0.2(0-1.5)$ & $1.5(0.4-5.7)$ & $0.4(0-29.9)$ & $1.5(0.7-3.6)$ & $2.0(0.7-5.4)$ \\
\hline Private - Not Shared & $38.2(30.0-47.0)$ & $56.3(50.9-61.5)$ & $68.2(59.8-75.6)$ & $72.7(64.3-79.7)$ & $71.1(62.7-78.2)$ & $64.7(56.8-71.8)$ \\
\hline Private - Shared with other household(s) & $18.5(13.2-25.2)$ & $42.7(37.7-48.0)$ & $29.6(22.1-38.5)$ & $26.2(19.4-34.3)$ & $27.1(19.9-35.7)$ & $32.5(24.9-41.2)$ \\
\hline Other/Unknown & $12.3(6.0-23.7)$ & $0.8(0.3-2.1)$ & $0.6(0-4.6)$ & $0.8(0.2-3.2)$ & $0.3(0-2.3)$ & $0.8(0.1-5.9)$ \\
\hline \multicolumn{7}{|l|}{ Sharing Accommodation - \% (95 \% Cl) } \\
\hline Not Sharing Accommodations & - & $66.0(56.9-74.1)$ & $64.9(56.4-72.6)$ & $67.1(59.6-73.7)$ & $59.5(51.7-66.8)$ & $68.9(61.3-75.6)$ \\
\hline Hosted - Sharing with a national & - & $2.3(1.1-5.1)$ & $13.2(7.9-21.3)$ & $8.3(4.5-15.0)$ & $13.2(9.1-18.8)$ & $12.6(8.2-18.9)$ \\
\hline Not Hosted - Sharing w/ 1 refugee $\mathrm{HH}$ & - & $20.7(15.2-27.6)$ & $12.3(8.2-18.1)$ & $14.8(10.3-20.8)$ & $15.7(10.8-22.1)$ & $9.8(6.3-15.0)$ \\
\hline Not Hosted - Sharing w/ $>1$ refugee $\mathrm{HH}$ & - & $10.9(7.3-16.0)$ & $9.5(6.3-14.1)$ & $9.9(6.2-15.4)$ & $11.7(7.6-17.5)$ & $8.7(5.3-13.8)$ \\
\hline
\end{tabular}


reported in pre-conflict national assessments of children in Syria-9.3 \% according to the 2009 SFHS and $8.6 \%$ according to the 2006 MICS [12, 14]. The prevalence estimates observed in our assessments are more similar to national estimates from neighboring countries now hosting refugees. Demographic Health Survey (DHS) data from Jordan in 2012 estimated a prevalence of $2.4 \%$ for total wasting and $0.6 \%$ for severe wasting [31]. A 2010 national micronutrient survey in Jordan similarly found the prevalence of total wasting among children 12 to 59 months to be $3.5 \%$ [32]. Estimated prevalence among long-term Palestinian refugees in Lebanon in 2011 also suggest wasting to be below crisis levels (4.7\%) [33]. Prevalence of wasting in Iraq documented in the 2011 MICS was slightly higher (7.4\%) [34]. These findings together suggest that at the time of the assessments, contrary to media reports and popular opinion, Syrian refugee children were not experiencing crisis levels of acute malnutrition but rather had levels comparable to the host populations among which they were displaced.

Whereas for acute malnutrition a change in prevalence from pre-crisis was observed, levels of stunting among refugees in most of our assessments were similar to estimates of stunting in Syria pre-crisis. This distinction is consistent with the fact that stunting is a measure of chronic malnutrition and is less affected by acute changes in food security. Stunting was estimated to be $23.0 \%$ in the 2009 SFHS and $22.4 \%$ in the 2006 MICS $[12,14]$. These pre-crisis levels are very similar to that estimated in North, South and Bekaa regions of Lebanon (range 20.1-21.0\%), and not markedly different from stunting prevalence in Za'atri refugee camp $(16.7 \%)$. Interestingly, the prevalence of stunting in our assessment of non-camp based refugees in Jordan was lower than in other contexts surveyed (10.5\%); this prevalence is more similar to the prevalence of stunting estimated in Jordan in the 2012 DHS (7.7 \%) than estimates from Syria pre-conflict [31]. Prevalence of stunting in our assessment of refugees in Beirut (14.1\%) was more similar to that estimated among Palestinian refugees in Lebanon (13.3\%) [33]. This may reflect a degree of integration of non-camp refugees with the host populations in Jordan and Beirut, Lebanon.

Levels of anemia recorded were high in all assessed settings, but only a problem of major public health significance in the Za'atari refugee camp in Jordan, according to WHO classification [22]. In Za'atari, prevalence of anemia was $48.4 \%$ among children aged 6 to 59 months and $44.8 \%$ among non-pregnant women. High prevalence of anemia among refugees has been documented in many camp-based refugee populations. A study of Bhutanese refugee children in Nepal documented a prevalence of $43.3 \%$ in 2007 , prior to introduction of micronutrient supplementation [35]. A study of refugees in long-term African refugee camps found even higher prevalence estimates among children in camps in Kenya (61.3\%), Uganda (72.9 \%), and Ethiopia (62.9 \%) [8]. High prevalence of anemia among refugees has been attributed in part to the reliance on food rations in camps, an explanation consistent with our finding that prevalence among the camp based refugees in Za'atri was higher than in non-camp based refugees in Jordan and in Lebanon $[7,8,35]$. In our assessments of non-camp based refugee populations, anemia levels were more consistent with the host populations. Among refugee children in Jordan living in the host population, total anemia prevalence in our survey was slightly lower (26.1\%) than that documented in the Jordanian population among children under five in the 2012 Jordan DHS (32.4 \%) [31]. Similarly, the prevalence of anemia among refugee women residing in host population in Jordan in our survey $(31.3 \%)$ was also just below the estimated prevalence from the 2012 Jordan DHS (33.5 \%).

For both women and children, prevalence of severe anemia was low, $1.1 \%$ or less in all surveys. In Lebanon, no cases of severe anemia were identified among children. Supplementation with micronutrient powder has been shown in a randomized trial to have no significant effect on hemoglobin levels among children with hemoglobin levels $\geq 10.0 \mathrm{~g} / \mathrm{dL}$ [36]. These findings have subsequently been confirmed in studies of Bhutanese refugee children [35]. As such, micronutrient powder supplementation may have negligible benefits in populations with a low prevalence of children with hemoglobin $<10.0 \mathrm{~g} / \mathrm{dL}$, as is the case among refugees in Lebanon and Jordan. Instead, interventions that help ensure a more diversified, micronutrient rich diet may better address the micronutrient deficiencies in the refugee populations than powders, particularly given the rich diversity of food available in markets outside the camps.

Self-reported data provided additional information to contextualize the nutrition findings. With respect to antenatal care, all six assessments in Jordan and Lebanon found that fewer than $55 \%$ of pregnant women 15-49 years of age were enrolled in ANC. Pre-crisis, Syria reported high utilization of reproductive health services. A reported $85.3 \%$ of pregnant women received ANC services one or more times during pregnancy in Syria; $93.0 \%$ of deliveries were attended by a skilled professional [12]. Declines in antenatal care coverage may in part be related to cost. Antenatal care in Syria was free or inexpensive relative to services in Jordan and Lebanon [37-39]. A cost barrier may also explain the higher enrollment in Za'atri refugee camp, where antenatal services are free and relatively easy to access compared to services out of camp in Jordan. Previous research from Lebanon suggests that unavailability of a reproductive health clinician is also a common barrier to receiving ANC [40]. The observation from 
our assessments that some women evidently buy ironfolate supplements but do not go for ANC visits may support this finding.

While these data on antenatal care provide some indication that access to reproductive care could be improved, we caution against over interpretation of these findings. Several studies have reported higher utilization of ANC services than we document. In Lebanon, a 2012 clinic based assessment found that among Syrian refugees, $73 \%$ of pregnant women reported at least one antenatal care visit [40]. A non-random, convenience sample of refugees in Lebanon estimated that $83 \%$ of pregnant refugee women attended at least one ANC visit [41]. In Jordan, a nationally representative surveys in 2014, estimated that $82 \%$ of Syrian refugees had made at least one ANC visit while pregnant [37]. Further analysis to explore whether these differences in coverage estimates are attributable to variations in selection of respondents, or whether they reflect true differences in health seeking behaviors, may be useful for scaling up reproductive health services in the region.

Prevalence of diarrhea in children was assessed in all surveys. Two week prevalence of diarrhea was highest in North Lebanon (33.3 \%) and Iraq's Domiz refugee camp $(32.8 \%)$. These data suggest an increase in diarrhea prevalence, compared to that reported among children $0-59$ in Syria pre-crisis $(8.1 \%)$ or the Iraqi population $(14.8 \%)$ [14, 34]. Notably, the prevalence of diarrhea in these settings is also high relative to that reported from other refugee camps, including Dadaab camps in Kenya (13.5 \%),Tongorara camp in Zimbabwe (21.4 \%), and Mai-Ain camp in Ethiopia (29.7 \%) [42-44].

This high prevalence is particularly notable given reported access to improved sanitation and safe water. In Lebanon and out of camp in Jordan, nearly all refugees had access to a private toilet; fewer than $2 \%$ of refugees in out of camp settings used public toilets. Even in Za'atri camp, less than a third of households reported using public toilets. For comparison, a global review of 90 refugee camps in 2005 found that on average latrines were shared by 27 people (range 5 to 1124 persons per latrine) [45]. Global analysis have shown an association between prevalence of diarrhea and shared sanitation facilities [46]. For out of camp refugees, the two most common primary sources of drinking water were running water and bottled water. Running water is an improved source of water as classified by the WHO, as is bottled water when another source of water is available for cooking and personal hygiene [47]. In Za'atri, the primary source of water was water tankers, an unimproved source of drinking water [47].

In all settings, reported prevalence of diarrhea was higher among children 0-23 months than children 24-59 months of age. In South and Bekaa regions of
Lebanon, prevalence among younger children was more than twice that of older children. The finding of higher diarrhea prevalence among younger children is consistent with previous literature. A 2012 systematic review of data from 72 studies concluded that while rates varied by country, in all regions incidence rates of diarrhea were lower among children aged 24-59 months than among children aged 0-23 months [48]. Data from a case-control study of rotavirus among refugees in Jordan, similarly found rotavirus prevalence was 2.4 times higher in children less than 24 months of age [49].

Current breastfeeding was assessed as a measure of infant and young child feeding practices. Among children under 6 months of age, current breastfeeding was lowest in Domiz refugee camp in Iraq. In Domiz, as well as Za'atri, we document a drop-off in current breastfeeding during the second year of life (12-23 months), such that the proportion breastfeeding in both camps is notably lower than that reported from out of camp refugees in Jordan and Lebanon. These differences may be related to pre-conflict factors, such as the place of origin in Syria and related cultural practices, or may be related to differences in the conditions in the camp that affect breastfeeding practices.

Results reported in this manuscript are subject to several limitations. First, these surveys were initially designed in each country to best inform ongoing emergency response activities. As a result, different survey instruments were used in each country. Results presented here are derived from questions that were reasonably similar across the settings. Standardization of additional questions, particularly questions related to water, sanitation and immunization would have allowed for more comparisons. Second, the assessment in Iraq used a different sampling method than either Jordan or Lebanon assessments. The Iraq survey was designed to be representative of households with children under 5 years of age, not of all households. This methodology did not allow for comparison on several household level indicators with other surveys. Third, self-reported indicators, such as feeding practices, diarrhea morbidity and access to antenatal care, may be subject to recall bias. Finally, no surveys were organized in Egypt or Turkey. Around the time of our surveys, approximately $23 \%$ of Syrian refugees were hosted in Turkey and $6 \%$ were hosted in Egypt. [4] Additionally, while the majority of Iraqi refugees have settled in urban areas, no assessments of non-camp refugees in Iraq were conducted [50]. However, given the similarities in the nutritional status of refugees across the settings assessed, we suggest it is likely that acute malnutrition among the refugees in Turkey, Egypt and non-camp Iraq is similar to those included in our assessments. 


\section{Conclusions}

Taken together, the seven surveys of Syrian refugees displaced to Iraq, Jordan, and Lebanon suggest that acute malnutrition was not a significant problem, however refugees from Syria, particularly those in Za'atri refugee camp, experienced elevated prevalence of anemia. In addition to these key findings, we highlight several additional indicators showing similar prevalence across settings and that are important triggers for public health action - low coverage of antenatal care relative to preconflict; high prevalence of diarrhea particularly among younger children $0-23$ months of age; and low prevalence of continued breastfeeding after 12 months of age.

Given that high prevalence of acute malnutrition is commonly associated with complex humanitarian emergencies, the initial focus of nutrition programming for Syrian refugees focused on treatment of acute malnutrition. However, the findings of these surveys suggest that a drive to scale up treatment of acute malnutrition may not always be the best allocation of scarce resources. While quality treatment of malnourished children at existing health centers remains a priority, these data encouraged a shift in focus of response activities.

Based on the results of these surveys, nutrition partners on the ground prioritized interventions to address micronutrient deficiencies through dietary diversity advocacy and support of food fortification. In Za'atri camp, UN partners transitioned from ration distributions to cash vouchers, a change which allows refugees to shop in markets which offered a wider variety of food, including fresh produce and meat, than that included in the rations. Promotion of appropriate IYCF practices were prioritized to encourage breastfeeding and appropriate introduction of complementary foods. Nutrition partners also recommended inter-sectoral collaboration to promote quality water and sanitation. Given little indication of a quick resolution to the conflict, it was recommended to continue monitoring the situation through periodic nutrition surveys and analysis of facility based surveillance.

\section{Additional file}

Additional file 1: Parameters for calculating sample size in Jordan and Lebanon surveys of Syrian refugees, 2013-2014 (DOCX 13 kb)

\begin{abstract}
Abbreviations
DHS, Demographic Health Survey; Hb, Hemoglobin; IYCF, Infant and young child feeding; MICS, Multiple Indicator Cluster Survey; SFHS, Syrian Family Health Survey; UNHCR, United Nations High Commissioner for Refugees; UNICEF, United Nations Children's Fund; WHO, World Health Organization
\end{abstract}

\section{Acknowledgements}

We acknowledge the contributions of the Syrian, Jordanian, Lebanese and Iraqi interviewers as well as the Syrian families who participated in this study. Additional gratitude is due to: United Nations High Commissioner for Refugees
(Douglas Jayasekaran, Ann Burton, Caroline Wilkinson, Ellen Andresen, Aye Aye Than); United Nations Children's Fund (Azzeddine Zeroual, Mohammad Amiri); World Food Program (Dorte Jessen); Mediar (Gabriele Faender); Jordanian MoH (Mohammed Tarawneh); International Orthodox Christian Charities (Sabeen Abdulsater, Marya Al Nawakil, Dima Ousta, Nanor Karaguezian); Republic of Lebanon MoPH; Duhok DoH; Kurdistan Regional Government; Jordan Health Aid Society; World Health Organization; and United Nations Population Fund.

\section{Role of funding}

No additional funding.

\section{Authors' contributions}

$\mathrm{MH}, \mathrm{EL}, \mathrm{JK}, \mathrm{OOB}$ designed the study, $\mathrm{MH}, \mathrm{EL}, \mathrm{JK}, \mathrm{OOB}$ collected the data, EL, $\mathrm{AAH}, \mathrm{OB}$ analyzed the data, $\mathrm{EL}, \mathrm{MH}$, and $\mathrm{OOB}$, interpreted the data, $\mathrm{EL}$ and $\mathrm{OOB}$ drafted the manuscript, $\mathrm{MH}, \mathrm{JK}, \mathrm{AAH}$ critically revised the manuscript for important intellectual content. $\mathrm{MH}, \mathrm{EL}, \mathrm{JK}, \mathrm{AAH}$, and $\mathrm{OOB}$ read and approved the final manuscript. All authors had full access to all of the data and take responsibility for the integrity of the data and the accuracy of the data analysis.

\section{Competing interests}

All authors declare that they have no competing interests; no support from any organisation for the submitted work; no financial relationships with any organisations that might have an interest in the submitted work in the previous 3 years; no other relationships or activities that could appear to have influenced the submitted work.

\section{Ethics approval and consent to participate}

Approval by the Center for Disease Control and Prevention (CDC) for secondary analysis of data collected in these surveys was granted based on CDC non-engagement in the human subject research and on the local approvals.

\section{Disclaimer}

The findings and conclusions in this report are those of the authors and do not necessarily represent the official position of the Centers for Disease Control and Prevention or United Nations Children Fund.

\section{Author details}

${ }^{1}$ Health and Nutrition, United Nations Children's Fund, Middle East and North Africa Region, P.O. Box 1551, Amman 11821, Jordan. ²Emergency Response and Recovery Branch, Division of Global Health Protection, Center for Global Health, Centers for Disease Control and Prevention, Building 2500, Mailstop E-22, 2500 Century Parkway NE, Atlanta, GA 30345, USA.

Received: 21 April 2016 Accepted: 8 August 2016

Published online: 16 November 2016

\section{References}

1. United Nations Security Council. Meeting of Security Council to Discuss Report of the Secretary-General on the Implementation of Security Council Resolutions 2139 (2014), 2165 (2014) and 2191 (2014) (S/2015/468). New York, 2014. http://www.un.org/en/sc/documents/sgreports/2015.shtml. Accessed 20 Apr 2016.

2. Blanchard CM, Humund CE, Nikitin MBD. Armed Conflict in Syria: Overview and U.S. Response. Congressional Research Service, 2015. https://www.fas. org/sgp/crs/mideast/RL33487.pdf. Accessed 20 Apr 2016.

3. Overview: 2015 Syria Response Plan (SRP) and 2015-2016 regional Refugee \& Resilience Plan (3RP). Berlin: 3RP, 2014. http://www.3rpsyriacrisis.org/ publications/. Accessed 20 Apr 2016.

4. Office for the Coordination of Humanitarian Affairs (OCHA). Humanitarian Bulletin: Syrian Arab Republic, 2013. http://www.unocha.org/node/159056. Accessed 20 Apr 2016.

5. United Nations High Commissioner for Refugees (UNHCR). Syria Regional Refugee Response Inter-agency Information Sharing Portal. Secondary Syria Regional Refugee Response Inter-agency Information Sharing Portal. http:// data.unhcr.org/syrianrefugees/regional.php. Accessed 4 Oct 2015.

6. Style $\mathrm{S}$, Tondeur $\mathrm{M}$, Wilkinson $\mathrm{C}$, et al. Operational guidance on the use of special nutritional products in refugee populations. Food Nutr Bull. 2013; 34(4):420-8

7. Kemmer TM, Bovill ME, Kongsomboon W, et al. Iron deficiency is unacceptably high in refugee children from Burma. J Nutr. 2003;133(12):4143-9. 
8. Seal AJ, Creeke PI, Mirghani Z, et al. Iron and vitamin A deficiency in longterm African refugees. J Nutr. 2005;135(4):808-13.

9. Longhurst R. Nutrition and care of young children during emergencies. Food Nutr Bull. 1995;16(4):407-12.

10. World Health Organization. Guiding principles for feeding infants and young children during emergencies. Geneva: World Health Organization; 2004. http://www.who.int/nutrition/publications/emergencies/9241546069/ en/. Accessed 20 Apr 2016.

11. Humphrey JH. Child undernutrition, tropical enteropathy, toilets, and handwashing. Lancet. 2009;374(9694):1032-5.

12. Central Bureau of Statistics Pan-Arab Project for Family Health. League of Arab States, United Nations Children's Fund. Syrian Arab Republic: Multiple Indicator Cluster Survey; 2006. http://www.childinfo.org/files/MICS3_Syria_ FinalReport_2006_Eng.pdf. Accessed 20 Apr 2016.

13. World Health Organization (WHO). Physical status: the use and interpretation of anthropometry. Report of a WHO Expert Committee. Technical Report Series No. 854. Geneva: World Health Organization, 1995. http://whqlibdoc.who.int/trs/WHO_TRS_854.pdf. Accessed 20 Apr 2016.

14. Health Syrian Ministry of Health. Family Health Survey in the Syrian Arab Republic. Damascus, 2009.

15. United Nations High Commissioner for Refugees. The Number of Syrian Refugees in Lebanon Passes the 1 Million Mark, 2014. http://www.unhcr. org/533cld5b9.html. Accessed 20 Apr 2016.

16. 2014 Syrian Arab Republic Humanitarian Assistance Response Plan (SHARP), 2013. http://reliefweb.int/sites/reliefweb.int/files/resources/2014_Syria_ SHARP.pdf. Accessed 20 Apr 2016.

17. Humanitarian Country Team. 2015 Strategic Response Plan: Syrian Arab Republic, 2014. http://reliefweb.int/sites/reliefweb.int/files/resources/2015_ SRP_Syria_EN_AdvanceCopy_171214.pdf. Accessed 20 Apr 2016.

18. United Nations Children Fund (UNICEF) and World Food Program (WFP). Interagency Nutrition Assessment: Syrian Refugees in Jordan Host Communities and Za'atri Camp. Amman, Jordan: UNICEF WFP, 2012. https:/data.unhcr.org/ syrianrefugees/download.php?id=2744. Accessed 20 Apr 2016.

19. United Nations Children Fund (UNICEF) and World Food Program (WFP) Inter-agency Nutrition Assessment: Syrian Refugees in Lebanon. Beruit, Lebanon: UNICEF WFP, 2013. http://reliefweb.int/sites/reliefweb.int/files/ resources/Nutrition\%20Assessment\%20Reort\%20\%20for\%20Syrian\%20 Refugees\%20in\%20Lebanon\%20-\%2031.01.13.pdf. Accessed 12 Jul 2016.

20. de Ville de Goyet C SJ, Geijer U. The Management of Nutritional Emergencies in Large Populations. Geneva: World Health Organization, 1978. http://apps.who.int/iris/handle/10665/39436. Accessed 20 Apr 2016.

21. Cohen AR, Seidl-Friedman J. HemoCue system for hemoglobin measurement. Evaluation in anemic and nonanemic children. Am J Clin Pathol. 1988;90(3):302-5.

22. World Health Organization (WHO). Haemoglobin concentrations for the diagnosis of anaemia and assessment of severity. In: System VaMNI, ed. Geneva: World Health Organization, 2011. http://www.who.int/vmnis/ indicators/haemoglobin.pdf. Accessed 20 Apr 2016.

23. United Nations Department of Technical Co-Operation for Development and Statistical Office. How to weigh and measure children: assessing the nutritional status of young children in household surveys. New York, NY: United Nations; 1986.

24. WHO child growth standards: Length/height-for-age, weight-for-age, weight-for-height and body mass index for-age: Methods and development. Geneva: World Health Organization, 2006.

25. Grijalva-Eternod CS, Wells JC, Cortina-Borja M, et al. The double burden of obesity and malnutrition in a protracted emergency setting: a crosssectional study of Western Sahara refugees. PLoS Med. 2012;9(10):e1001320.

26. Standardized Monitoring and Assessment of Relief and Transitions (SMART). Measuring mortality, nutritional status, and food security in crisis situations: SMART methodology, version 1, 2006. http:// smartmethodology.org/survey-planning-tools/smart-methodology/. Accessed 20 Apr 2016.

27. Ververs MT, Antierens A, Sackl A, et al. Which anthropometric indicators identify a pregnant woman as acutely malnourished and predict adverse birth outcomes in the humanitarian context? PLoS Curr. 2013;5. http://www. ncbi.nlm.nih.gov/pmc/articles/PMC3682760/.

28. ENA for SMART. ENA for SMART - Software for Emergency Nutrition Assessment. Secondary ENA for SMART - Software for Emergency Nutrition Assessment 2011. http://www.nutrisurvey.net/ena/ena.html. Accessed 20 Apr 2016.
29. Donner A, Klar N. Design and Analysis of Cluster Randomization Trials in Health Research. London: Oxford University Press; 2000. p. 79-97.

30. Physicians Across Continents (PAC). SMART Methodology Nutrition Assessment Idleb Governorate, Syria, 2014. https://www. humanitarianresponse.info/sites/www.humanitarianresponse.info/files/ assessments/SMART_Idleb_Survey_Final_Report.pdf. Accessed 20 Apr 2016.

31. Department of Statistics (Jordan), ICF International. Jordan: Population and Family Health Survey 2012. Calverton, Maryland, USA: Department of Statistics and ICF International, 2012. https://dhsprogram.com/pubs/pdf/ FR282/FR282.pdf. Accessed 20 Apr 2016.

32. Jordan Ministry of Health (MOH), Global Alliance for IMproved Nutrition (GAIN), United States Center for Disease Control and Prevention (CDC), et al. National Micronutrient Survey Jordan 2010, 2011. http://www.gainhealth.org/ knowledge-centre/jordan-micronutrient-survey-report/. Accessed 20 Apr 2016.

33. Palestinian Central Bureau of Statistics, United Nations Children's Fund. Palestinian Refugee Camps, Lebanon: Multiple Indicator Cluster Survey, 2011. http://mics.unicef.org/surveys. Accessed 20 Apr 2016.

34. Central Statistics Organization, Kurdistan Regional Statistics Office, Ministry of Health, et al. Iraq: Multiple Indicator Cluster Survey, 2011. http://mics. unicef.org/surveys. Accessed 20 Apr 2016.

35. Bilukha O, Howard C, Wilkinson C, et al. Effects of multimicronutrient home fortification on anemia and growth in Bhutanese refugee children. Food Nutr Bull. 2011;32(3):264-76.

36. Zlotkin SH, Schauer C, Christofides A, et al. Micronutrient sprinkles to control childhood anaemia. PLoS Med. 2005;2(1):e1.

37. Johns Hopkins University Bloomberg School of Public Health, The World Health Organization, The School of Nursing at Jordan University for Science and Technology, et al. Syrian Refugee Health Access Survey in Jordan December 2014, 2014. http://reliefweb.int/report/jordan/syrian-refugeehealth-access-survey-jordan-december-2014. Accessed 20 Apr 2016.

38. Sami S, Williams HA, Krause S, et al. Responding to the Syrian crisis: the needs of women and girls. Lancet. 2014;383(9923):1179-81.

39. Bashour H, Abdulsalam A, Jabr A, et al. Maternal mortality in Syria: causes, contributing factors and preventability. Trop Med Int Health. 2009;14(9):1122-7.

40. Reese Masterson A, Usta J, Gupta J, et al. Assessment of reproductive health and violence against women among displaced Syrians in Lebanon. BMC Womens Health. 2014;14(1):25.

41. Benage $M$, Greenough PG, Vinck P, et al. An assessment of antenatal care among Syrian refugees in Lebanon. Confl Health. 2015;9:8.

42. United Nations High Commissioner for Refugees. Preliminary Report: Standardised Expanded Nutrition Survey (SENS): Tongogara Refugee Camp, Zimbabwe, 2012. http://sens.unhcr.org/wp-content/uploads/2015/03/Tool_ 17_SENS_Pre-Module_ZIMBABWE_PRELIMINARY_SENS_REPORT_2012_-v2. doc. Accessed 20 Apr 2016.

43. United Nations High Commissioner for Refugees. Nutrition Survey Dadaab Refugee Camps: Hagadera, Ifo, and Dagahaley Camps \& Dagahaley Outskirts, 2011. http://www.ennonline.net/nutritionsurveyshagadera. Accessed 20 Apr 2016.

44. Kelati H, Mengiste B, Alemayehu T, et al. Prevalence of acute malnutrition and its associated factors among children aged 6-59 months in Mai-Aini Eritrean Refugees' Camp, Northern Ethiopia. J Nutr Food Sci. 2014:5(1):336.

45. Cronin AA, Shrestha D, Cornier N, et al. A review of water and sanitation provision in refugee camps in association with selected health and nutrition indicators-the need for integrated service provision. J Water Health. 2008;6(1):1-13.

46. Fuller JA, Clasen T, Heijnen M, et al. Shared sanitation and the prevalence of diarrhea in young children: evidence from 51 countries, 2001-2011. Am J Trop Med Hyg. 2014;91(1):173-80.

47. World Health Organization. WHO/UNICEF joint monitoring report, 2012. http://www.who.int/water_sanitation_health/monitoring/jmp2012/key_ terms/en/. Accessed 20 Apr 2016.

48. Fischer Walker CL, Perin J, Aryee MJ, Boschi-Pinto C, Black RE. Diarrhea incidence in low- and middle-income countries in 1990 and 2010: a systematic review. BMC Public Health. 2012;12:220.

49. Nimri LF, Hijazi S. Rotavirus-associated diarrhoea in children in a refugee camp in Jordan. J Diarrhoeal Dis Res. 1996;14(1):1-4.

50. United Nations High Commissioner for Refugees. Information Kit No. 12 Syrian Refugees - Iraq: Humanitarian Inter-Agency Interventions - 2nd Quarterly Report: 2015 April, May, June, 2015. http://data.unhcr.org/ syrianrefugees/download.php?id=9263. Accessed 20 Apr 2016. 